\title{
Startle responsivity following telencephalic lesions in the rat
}

\author{
ROBERT J. KIRKBY \\ Lincoln Institute, Melbourne, Australia
}

\begin{abstract}
Thirty-six adult male Wistar rats were tested individually in an automated apparatus to assess startle reactivity. Three days after testing, 12 rats underwent bilateral electrolytic lesioning of the dorsolateral frontal cortex, 12 rats received lesions to the anterodorsal caudate nuclei, and the remaining 12 rats served as unoperated controls. Thirty-six days after the surgical procedure, startle reactivity was reassessed. The rats with lesions of the dorsolateral frontal cortex were significantly more responsive to startle stimuli, but showed significantly faster habituation than the caudate-lesioned or unoperated groups. It was suggested that the heightened startle responsivity and the increased habituation could reflect the interaction of hyperreactivity and reduced fearfulness resulting from lesions of the frontal cortex.
\end{abstract}

A mammalian animal stimulated by a sudden and intense sound typically reacts with a "startle response" involving a generalized flexion of the total body, starting cephalically and progressing downwards to terminate with a sharp thrust of the extremities (Landis \& Hunt, 1939). It has been generally accepted that the brainstem arousal system plays an essential role in the startle response (see, for example, Lynn, 1966). Similarly, most models of habituation to repeated startle stimulation involve the concept of inhibition of reticular function (see, for example, Groves, Wilson, \& Miller, 1976). Neurophysiological evidence has implicated areas of the anterior forebrain, particularly the frontal cortex and caudate nucleus, in the inhibition of reticular arousal processes. Additionally, it has been reported that damage to these structures can result in increased reactivity to environmental stimuli (Kirkby, 1973).

The present study was undertaken to further investigate the role of the frontal cortex and caudate nucleus in the control of arousal mechanisms.

\section{METHOD}

Thirty-six male albino Wistar rats supplied by the C.S.I.R.O. served as subjects. The animals were kept in the laboratory for several weeks prior to commencement of experimentation and underwent intensive preexperimental handling and gentling procedures. During the experimental period, the rats were housed singly with free access to food and water.

Twelve rats had two lesions placed in each of the caudate nuclei, 12 rats had three lesions placed in each of the frontal cortices, and 12 rats served as unoperated controls. At the time of surgery, the subjects were approximately 120 days old and weighed $350-450 \mathrm{~g}$. The surgical technique has been outlined in detail (Kirkby, 1973). Briefly, the current parameters were $1.5 \mathrm{~mA}$ for $90 \mathrm{sec}$. For the anterior cortical lesions, the electrode placements were $2.1,2.6$, and $3.1 \mathrm{~mm}$ anterior to bregma, $2.2 \mathrm{~mm}$

Please forward reprint requests to Dr. R. J. Kirkby, Lincoln Institute, Carlton, Victoria, Australia, 3053. lateral to the midline, and $1.0 \mathrm{~mm}$ below the surface of the skull. The caudate nucleus lesions were aimed $2.1 \mathrm{~mm}$ anterior to bregma, $2.2 \mathrm{~mm}$ lateral to the midline, and 4.5 and $5.5 \mathrm{~mm}$ below the surface of the skull. These coordinates were in reference to the incisor bar adjusted to stand $3 \mathrm{~mm}$ above the level of the ear bars.

The apparatus has been described fully by Kirkby, Bell, \& Preston (1972). It involved an acrylic compartment $(24 \times 17.5 \times$ $13.5 \mathrm{~cm}$ ) placed within a larger ventilated and illuminated box. The startle response was measured as a downward thrust on a metal baseplate in the acrylic box. Depression of the baseplate moved an acrylic rod, which in turn displaced a ferrous lever. This disrupted the magnetic field surrounding a coil and induced a voltage change which was fed into an Offner Type R.S. Dynograph, where the magnitude of startle response was recorded in terms of pen deflection. The auditory startle stimulus was provided by a Hewlett-Packard 200 C.D. wide-range oscillator fed through an audio amplifier to the speaker mounted in the top of the acrylic box. The signal was set at $1,200 \mathrm{cps}, 106 \mathrm{~dB}$ at $1,000 \mathrm{~Hz}$ at rat head level against a background level of $43 \mathrm{~dB}$ provided by noise from the ventilating fan and other nearby equipment. The stimulus (approximately $100 \mathrm{msec}$ in duration) was presented automatically every $5 \mathrm{sec}$, a temporal gap long enough to attenuate possible effects of "prepulse inhibition" (Ison \& Hammond, 1971; Ison \& Krauter, 1974).

The rat was taken from its home cage, carried to the experimental room by hand, and placed in the apparatus. The subject was left in the box for a 20-min habituation period: at the end of this period the rat invariably appeared to have settled down and in several instances was asleep. To ensure that the subject was alert at the commencement of auditory stimulation, the animal was picked up and then replaced in the apparatus, the recorder was switched on, and the animal was presented with 80 stimuli, spaced $5 \mathrm{sec}$ apart. At the end of the stimulation period, the equipment was turned off and the rat returned to its home cage. The apparatus was cleaned with disinfectant prior to the next trial. The subjects were tested 3 days prior to, and 36 days after, surgery.

\section{RESULTS}

At the conclusion of the experiment, the rats with lesions of the caudate nucleus were killed and their brains perfused first with saline and then Formalin. The brains with lesions of the cortex were photographed with the area of tissue damage outlined with 
dye. Blocks of tissue containing the lesions were cut from the brains, mounted on a freezing-head microtome, and sliced at $20-\mu \mathrm{m}$ intervals; the extent of tissue damage was inspected from the frozen block.

All striatal lesions were contained within the dorsal-central aspect of the head of the caudate nucleus. There was some damage to extrastriatal tissue, generally unilateral. For example, one brain showed slight unilateral involvement of the globus pallidus. Another showed invasion of the most inferior aspects of the corpus callosum. Other structures minimally damaged in individual brains included the ventricular wall, the nucleus accumbens septi, and the nucleus lateralis septi. In location and size, the lesions were very similar to those illustrated in previous studies using the same lesion parameters (Kirkby, 1973; Kirkby \& Polgar, 1974).

Inspection of the brains from the frontal group showed that the lesions were generally restricted to the superior aspects of the cortex and in every case involved Areas 10, 6, and 4 bilaterally (Krieg, 1946). In a few brains, there was slight encroachment on surrounding aspects of the cortex: Areas 2, 3, or 24. The lesions in the frontal cortex appeared to involve a larger area of tissue than those restricted to the striatum. The extent of cortical damage in two representative brains is illustrated in Figure 1.

The results are shown in Figure 2. Differences in startle responsivity, as reflected in mean responses over 80 trials, were tested by analysis of variance. No significant differences between groups were found in the analysis of preoperative startle scores $(\mathrm{F}<1$; df $=3,33)$. Because of the expectations based on evidence in the literature, the planned contrast technique of analysis of variance could be used to treat the postoperative scores. This analysis showed that the startle scores of the subjects with lesions of the frontal cortex were significantly greater than those of the unoperated group $(F=3.40 ; \mathrm{df}=3,33 ; \mathrm{p}<.05)$. The scores of the



Figure 1. The extent of frontal cortex damage in two subjects with startle scores about the median. The area of lesion has been stained with black ink.

caudotomized subjects fell between those of the frontal cortex and unoperated groups.

To examine effects over the total 80 startle trials, the data were tabulated in a group by trials format, and the curves analyzed and compared by the technique suggested by Grant (1956). Treatment of the preoperative startle scores showed that the overall magnitude of the 80 startle scores differed between individual subjects $(F=15.4$; $\mathrm{df}=3,33$; $\mathrm{p}<.002)$, that the curves were significantly linear $(\mathrm{F}=19.0 ; \mathrm{df}=1 ; \mathrm{p}<.001)$, and that the slopes of the curves did not differ between groups $(F<1)$. Treatment of the postoperative data showed that startle scores differed significantly between subjects $(\mathrm{F}=17.1 ; \mathrm{df}=3,33 ; \mathrm{p}<.001)$ and that there was a significant linear interaction between curves $(\mathrm{F}=$
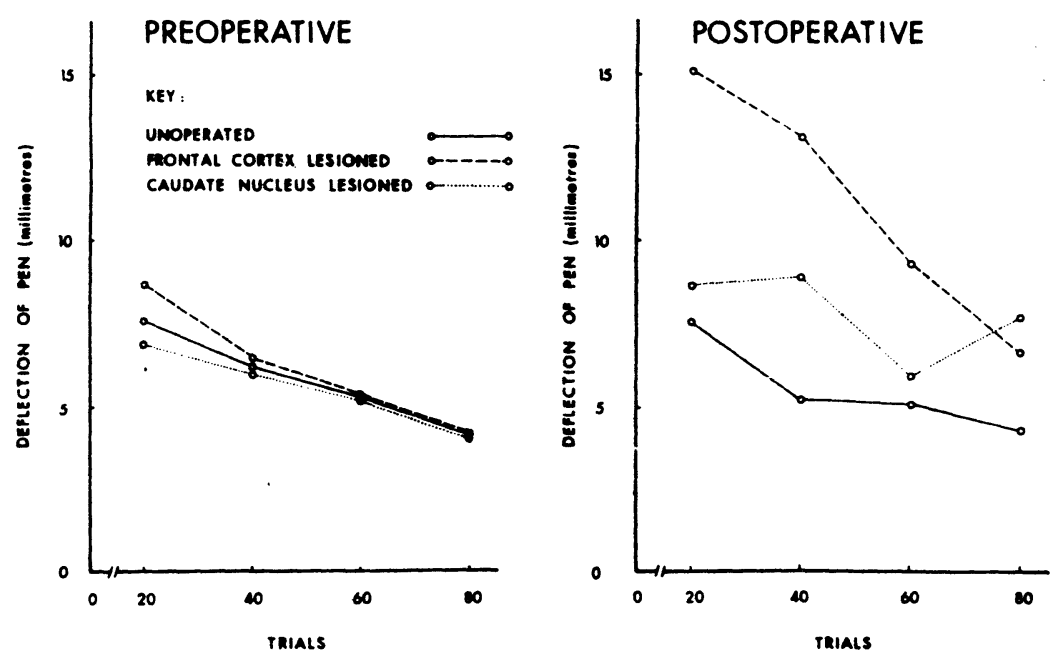

Figure 2. The responsivity of rats to successive startle stimuli prior to, and after lesions involving the dorsolateral frontal cortices or the anterodorsal caudate nuclei. 
3.73; $\mathrm{df}=2,33 ; \mathrm{p}<.05$ ), indicating that the slopes of the curves differed between groups.

To further investigate the apparent changes in startle reactivity over postoperative trials, an index of habituation was calculated for every animal. This score was arrived at by subtracting from the total of the first quartile scores (Trials 1-20) the total of scores of the final quartile (Trials 60-80). Each subject then had a single score taken to represent its individual rate of habituation. The scores for each group were compared. Preoperatively, the habituation scores did not differ between groups $(F<1)$. Analysis of variance of the postoperative scores revealed that differences existed between the groups $(F=5.22 ; \mathrm{df}=3,33 ; \mathrm{p}<.01)$. These differences were tested by the Newman-Keuls procedure. The post hoc comparisons showed that habituation scores were significantly greater for the frontal cortex lesion than either the caudotomized $\left(q^{3}=4.46\right.$; $\mathrm{df}=3,33 ; \mathrm{p}<.01)$ or the unoperated group $\left(\mathrm{q}^{2}=\right.$ $3.08 ; \mathrm{df}=2,33 ; \mathrm{p}<.05)$. The caudate nucleus lesion and unoperated groups were not significantly different $\left(q^{1}=2 \cdot 37 ; d f=2,33\right)$.

\section{DISCUSSION}

In the present study, preoperative testing revealed no significant differences between groups in either magnitude of startle response or rate of habituation. Following surgery, rats with lesions of the dorsolateral frontal cortex were significantly more responsive to startle stimuli than the caudate nucleus lesion group or the unoperated control group. The frontal cortex lesion animals also showed a significantly more rapid rate of habituation than either of the other groups.

The finding of increased startle responsivity associated with rapid habituation does not seem consistent with earlier reports of an inverse association between level of arousal and rate of habituation (Davis \& Wagner, 1969). The increased startle responsivity of the frontal cortex rats was predicted preexperimentally: hyperreactivity to auditory stimuli in subjects with lesions of the frontal cortex has been reported previously and appears to be a wellestablished phenomenon (Gross, 1963; Isaac \& DeVito, 1958; Stepien \& Stepien, cited in Brutkowski, 1965, p. 734). The Stepien and Stepien report is particularly relevant to the present findings. They reported that dogs with lesions in the premotor aspect of the frontal cortex evidenced an exaggerated orienting response to repetitions of an auditory signal. Even more relevant to the present study were the observations of Hammond (1974) indicating increased startle reactivity in rats with lesions of the frontal cortex. It is noteworthy that Hammond's findings suggested a relationship between increased responsivity and damage to the medial aspects of the frontal cortex.
The increased rate of habituation was an unexpected result. Studies by several investigators have suggested that lesions of the frontal cortex inhibit habituation processes. In learned behavior, slower habituation has been reflected in tendencies to perseverate, that is, to continue responding in well-practiced patterns of behavior no longer appropriate to the situation (French, Birnbaum, Levine, \& Pinsker, 1967; Mishkin, 1964; Wilson \& Oscar, 1966). In investigations of innate behaviors, slower habituation following frontal cortex damage has been reported for flexor-withdrawal reflexes (Griffin \& Pearson, 1968) and head-shaking responses (Roydes, 1970). In a recent study, Groves, Wilson, and Boyle (1974) reported that habituation to startle stimuli was not significantly affected by lesions of the frontal cortex.

In all three of the above experiments, the lesions were generally restricted to the anterior frontal poles and, unlike those of the present study, did not typically involve the dorsolateral region. Possibly, there is a close relationship between the specific locus of frontal cortex damage and rate of habituation of unlearned responses in the rat.

Another possible explanation of the startle behavior of the rats with lesions of the frontal cortex involves a fearfulness-reduction hypothesis. It appears acceptable that the heightened levels of startle shown by the frontal rats in the initial trials represented increased reactivity. It could be that this hyperreactivity is obscured in later trials by rapid reductions in fearfulness. Lowered fearfulness in animals with lesions of the frontal cortex has been reported by several investigators (Lichenstein, 1950; Pribram \& Weiskrantz, 1957; Streb \& Smith, 1955; Waterhouse, 1957).

Although the present findings did not reveal any significant differences between the caudotomized and the unoperated rats in levels of startle responsivity or in rates of habituation, the differences were in the predicted direction. Previous studies have indicated that hyperreactivity in the rat varies with the extent of damage to the anterodorsal caudate nuclei (Kirkby, 1973). Perhaps further experimentation, using preparations with more extensive caudate damage, could uncover significantly increased startle responsivity and significantly decreased habituation in striatal animals.

\section{REFERENCES}

BRutkowski, S. Functions of prefrontal cortex in animals. Physiological Review, 1965, 45, 721-746.

Davis, M., \& WAgNER, A. R. Habituation of startle response under incremental sequence of stimulus intensities. Journal of Comparative and Physiological Psychology, 1969, 67, 486-492.

French, G. M., Birnbaum, I., Levine, R., \& Pinsker, H. Discriminative choice in normal and prefrontal rhesus monkeys. Journal of Comparative and Physiological Psychology, 1965, 59. 225-230. 
Grant, D. A. Analysis of variance tests in the analysis and comparison of curves. Psychological Bulletin, 1956, 53, 141-154.

Griffin, J. P., \& Pearson, J. A. The effect of lesions of the frontal areas of the cerebral cortex on habituation of the flexor withdrawal response in the rat. Brain Research, 1968, 8, 177-184.

Gross, C. G. Locomotor activity following lateral frontal lesions in rhesus monkeys. Journal of Comparative and Physiological Psychology, 1963, 56, 232-236.

Groves, P. M., Wilson, C. J., \& Boyle, R. D. Brain stem pathways, cortical modulation and habituation of the acoustic startle response. Behavioral Biology, 1974, 10, 391-418.

Groves, P. M., Wilson, C. J., \& Miller, S. W. Habituation of the acoustic startle response. A neural system analysis of habituaction in the intact animal. In A. Riesen \& R. F. Thompson (Eds.), Advances in psychobiology (Vol. 3). New York: Wiley, 1976.

Hammond, G. R. Frontal cortical lesions and prestimuius inhibition of the rat's acoustic startle reaction. Physiological Psychology, 1974, 2, 151-156.

Is AAC. W.. \& DEVITo, J. L. Effect of sensory stimulation on the activity of normal and frontal lobectomized monkeys. Journal of Comparative and Physiological Psychology, 1958, 51, 172-174.

Ison, J. R., \& Hammond, G. R. Modification of the startle reflex in the rat by changes in the auditory and visual environments. Journal of Comparative and Physiological Psychology, 1971, 75, 435-452.

Ison. J. R.. \& Krauter, E. E. Reflex inhibiting stimuli and the refractory period of the acoustic startle response in the rat. Journal of Comparative and Physiological Psychology, 1974, 86, 420-425.

KIRKBY, R. J. The caudate nucleus and arousal in the rat. Journal of Comparative and Physiological Psychology, 1973, 85, 82-96.

Kirkby, R. J., Bell, D. S., \& Preston, A. C. The effects of methylamphetamine on stereotyped behaviour, activity, startle. and orienting responses. Psychopharmacologia, 1972, 25, 41-48.
Kirkby, R. J., \& Polgar, S. Active avoidance in the laboratory rat following lesions of the dorsal or ventral caudate nucleus. Physiological Psychology, 1974, 2, 301-306.

KRIEG. W. J. Connections of the cerebral cortex. I. The albino rat. A topography of the cortical areas. Journal of Comparative Neurology, 1946, 84, 221-259.

LANDIs, C., \& Hunt, W. A. The startle pattern. New York: Farrer \& Rinehart, 1939.

LICHENSTEIN, P. E. Studies of anxiety. II. The effects of lobotomy on a feeding inhibition in dogs. Journal of Comparative and Physiological Psychology, 1950, 43, 419-427.

LynN, R. Attention, arousal and the orientation reaction. Oxford: Pergamon Press, 1966.

Mishkin, M. Perseveration of central sets after frontal lesions in monkeys. In J. M. Warren \& K. Akert (Eds.), The frontal granulur cortex and behavior. New York: McGraw-Hill, 1964.

Pribram. K. H., \& Weiskrantz, L. A comparison of the effects of medial and lateral cerebral resections on conditioned avoidance behavior in monkeys. Journal of Comparative and Physiological Psychology, 1957, 50, 74-80.

Roydes, R. L. Frontal lesions impair habituation of the headshake response in rats. Physiology and Behavior, 1970, 5, 1133-1139.

Streb, J. M., \& SMIth, K. Frontal lobotomy and the elimination of conditioned anxiety in the rat. Journal of Comparative and Physiological Psychology, 1955, 48, 126-129.

WATERHOUSE, I. K. Effects of prefrontal lobotomy on conditioned fear and food responses in monkeys. Journal of Comparative and Physiological Psychology, 1957, 50, 81-88.

Wilson, W. A., \& Oscar, M. Probability learning in monkeys with lateral frontal lesions. Journal of Comparative and Physiological Psychology, 1966, 62, 462-464.

(Received for publication January 30, 1976; revision accepted April 21, 1976.) 